\title{
Adubação com nitrogênio e potássio em mudas de goiabeira em viveiro comercial
}

\section{Fertilization with nitrogen and potassium in guava seedlings in a commercial nursery}

\author{
Maria Jacqueline Thomazini Dias ${ }^{1 *}$; Henrique Antunes de Souza ${ }^{2}$; \\ William Natale 3 ; Viviane Cristina Modesto ${ }^{4}$; Danilo Eduardo Rozane ${ }^{5}$
}

\section{Resumo}

A adubação assume papel fundamental na fase de produção de mudas de frutíferas, a fim de garantir bom desenvolvimento e precocidade de produção. Objetivou-se avaliar os efeitos de doses de nitrogênio e potássio no crescimento de mudas de goiabeira. Estacas herbáceas de goiabeiras, cultivar "Paluma", foram enraizadas em câmara de nebulização, em sacos de polietileno contendo substrato. $\mathrm{O}$ experimento foi conduzido em viveiro comercial, em blocos casualizados, em esquema fatorial $4 \mathrm{x} 4$, sendo quatro doses de nitrogênio $\left(0,552,828\right.$ e $\left.1.104 \mathrm{mg} \mathrm{dm}^{-3}\right)$ e quatro doses de potássio $(0,726,1.089$ e 1.452 $\left.\mathrm{mg} \mathrm{dm}{ }^{-3}\right)$, com três repetições e três plantas por parcela. No enchimento dos sacos $\left(1,5 \mathrm{dm}^{-3}\right)$, foram adicionados $100 \mathrm{mg} \mathrm{dm}^{-3} \mathrm{de} \mathrm{P}$, enquanto os adubos contendo nitrogênio e potássio foram parcelados em três vezes. As mudas foram avaliadas aos 120 dias. Observou-se efeito significativo do nitrogênio nas variáveis altura, diâmetro do caule, número de folhas, índice SPAD, massa seca de folhas, caule, total, índice de qualidade de Dickson e acúmulo de N. A adubação com potássio não promoveu diferenças significativas nos parâmetros biométricos, índice SPAD e IQD.

Palavras-chave: Psidium guajava, fertilização nitrogenada, fertilização potássica, substrato

\begin{abstract}
The fertilization takes key role at the production of fruit seedlings in order to ensure a good development and early production. The aim of this study was to evaluate the effects of nitrogen and potassium on the growth of guava seedlings. Herbaceous stakes of guava, "Paluma" cultivar, were rooted in a mist room, in polyethylene bags containing substrate. The experiment was conducted in a commercial nursery, in randomized blocks and a factorial scheme $4 \times 4$, with four doses of nitrogen $(0,552,828$ and $1104 \mathrm{mg}$ $\left.\mathrm{dm}^{-3}\right)$ and four doses of potassium $\left(0,726,1,089\right.$ and $\left.1,452 \mathrm{mg} \mathrm{dm}^{-3}\right)$ in three replications and three plants for parcel. During the filling of the bags $\left(1,5 \mathrm{dm}^{-3}\right)$, were added $100 \mathrm{mg} \mathrm{dm}^{-3}$ of superphosphate, while fertilizers containing nitrogen and potassium were split into three times. After 120 days, the seedlings were evaluated. There was a significant effect of nitrogen in the variables height, stem diameter, number of leaves, SPAD index, dry weight of leaves, stems, total, Dickson quality index, and nitrogen accumulation. The fertilization with potassium did not influence the biometric parameters, SPAD index and Dickson quality index.
\end{abstract}

Key words: Psidium guajava, nitrogen fertilization, potassium fertilization, substrate

\footnotetext{
${ }^{1}$ Eng $^{\mathrm{a}}$ Agr ${ }^{\mathrm{a}}$, Universidade Estadual Paulista, UNESP. Campus de Jaboticabal, SP. E-mail: jacquelinethomazini@gmail.com

2 Pesquisador Embrapa Caprinos e Ovinos, Sobral, CE. E-mail: henrique@cnpc.embrapa.br

${ }^{3}$ Prof. Adjunto da UNESP, Dept ${ }^{\circ}$ de Solos e Adubos, Campus de Jaboticabal, SP. E-mail: natale@fcav.unesp.br

${ }^{4}$ Pós-Graduanda em Agronomia da UNESP, Dept ${ }^{\circ}$ de Produção Vegetal, Campus de Jaboticabal, SP. E-mail: vivianemodesto@ hotmail.com

${ }^{5}$ Prof. Dr. da UNESP, Campus Experimental de Registro, SP. E-mail: danilorozane@registro.unesp.br

* Autor para correspondência
} 


\section{Introdução}

Entre as frutíferas do estado de São Paulo, podese destacar a cultura da goiaba, que ocupa posição importante em várias regiões do interior paulista, seja para consumo in natura da fruta, seja para destinação às atividades das agroindústrias, que a utilizam para o processamento de diversos produtos.

Com uma nutrição adequada, mudas e plantas em produção ficam menos suscetíveis ao ataque de pragas e doenças, toleram melhor períodos de seca e outros estresses, além de elevar a produtividade e a qualidade dos frutos. A adubação realizada nos viveiros de mudas, porém, ainda é feita de maneira empírica, empregando-se formulados e aplicandose doses iguais em todas as plantas, sem distinção de cultivar ou mesmo de idade. Entretanto, cada vez mais, exigem-se cuidados e controles na produção das mudas, etapa esta crucial para a implantação de um pomar sadio, longevo e com início de produção precoce.

O nitrogênio e o potássio são os dois nutrientes mais requeridos pela goiabeira (FRANCO et al., 2007), e possuem um papel fundamental nos estádios iniciais de desenvolvimento das mudas, devendo seu parcelamento considerar a exigência das plantas, a cinética de absorção dos elementos e a dinâmica dos nutrientes no substrato. Em geral, a quantidade de nutrientes presentes nos substratos comerciais (forma disponível) é suficiente para o primeiro estágio de crescimento das mudas, porém, há necessidade de adubação para a planta completar seu ciclo de desenvolvimento no viveiro. Para a produção de mudas de goiabeira, não se dispõe, ainda, de informações técnicas sobre adubação básica em viveiro, havendo trabalhos sobre correção de acidez, micronutrientes e fósforo, porém, todos empregando solo como substrato.Além disso, muitos experimentos são conduzidos em condições diferentes daquelas observadas nos viveiros comerciais, dificultando a transferência de tecnologia.

Por haver, ainda, poucas informações sobre as necessidades das mudas de goiabeiras em nutrientes, objetivou-se avaliar o crescimento dessa frutífera em função da aplicação de diferentes doses de nitrogênio e potássio em viveiro comercial.

\section{Material e Métodos}

O trabalho foi conduzido na área de produção de mudas do Sítio São João, situado no município de Taquaritinga-SP, localizado a $21^{\circ} 44^{\prime} 44^{\prime \prime}$ de latitude sul e a $48^{\circ} 29^{\prime} 53^{\prime \prime}$ de longitude a oeste, com altitude de $512 \mathrm{~m}$. O clima da região pode ser classificado, segundo Köeppen, como Cwa, subtropical com chuvas de verão, e inverno relativamente seco.

Utilizaram-se mudas de goiabeira cultivar "Paluma", a mais plantada em todo o Brasil, obtidas a partir de propagação vegetativa de matrizes selecionadas e podadas 70 dias antes da retirada das estacas herbáceas. As estacas, compostas de um segmento de haste com um par de folhas, foram inicialmente mantidas em câmara de nebulização com aplicação intermitente de água, por um período de 90 dias até enraizarem. Em seguida, foram transplantadasdacâmaradenebulizaçãoparaoviveiro coberto com sombrite $30 \%$, sendo acondicionadas em sacos de polietileno $(14 \times 22 \mathrm{~cm})$ de volume de $1,5 \mathrm{dm}^{-3}$, contendo substrato à base de casca de pinus (Multiplant $\AA$ ) e colocadas em bancadas sem espaçamento entre os sacos. As características de concentrações totais e concentrações disponíveis de nutrientes no substrato, realizadas no Instituto Agronômico de Campinas, encontram-se nas Tabelas 1 e 2, respectivamente. O viveiro possuía sistema de irrigação por microaspersão, o qual era acionado diariamente de maneira que não ocorresse encharcamento do substrato contendo as mudas.

No momento do transplante das mudas para o viveiro, foram adicionados $100 \mathrm{mg} \mathrm{dm}^{-3}$ de $\mathrm{P}$ no enchimento dos sacos, tendo como fonte o superfosfato simples, seguindo a recomendação de Boaventura et al. (2004), que trabalhou com citrus, em substrato a base de casca de pinus. Para a goiabeira, Corrêa et al. (2003) recomendam a aplicação de $100 \mathrm{mg} \mathrm{dm}^{-3}$ de $\mathrm{P}$, trabalhando com substrato de subsolo (Argissolo Vermelho-Amarelo). 
Tabela 1. Análise do substrato empregado no experimento para as concentrações totais dos nutrientes.

\begin{tabular}{cccccccccccccc}
\hline $\mathbf{p H}$ & $\mathbf{N}$ & $\mathbf{P}$ & $\mathbf{K}$ & $\mathbf{C a}$ & $\mathbf{M g}$ & $\mathbf{S}$ & $\mathbf{B}$ & $\mathbf{C u}$ & $\mathbf{F e}$ & $\mathbf{M n}$ & $\mathbf{Z n}$ & Umidade & $\begin{array}{c}\text { Carbono } \\
\text { Orgânico }\end{array}$ \\
\hline & -0 & & & & &
\end{tabular}

pH em água 1:1,5. Concentração total: P, K, Ca, Mg, S, B, Cu, Fe, Mn, Zn: Extração nítrico-perclórico e determinação: ICP-OES., Umidade $65^{\circ} \mathrm{C}$. Resultados para os teores totais de carbono e nitrogênio foram feitos pelo novo equipamento de análise elementar de CNS (marca ELEMENTAR CNS).

Fonte: Instituto Agronômico de Campinas (IAC).

Tabela 2. Análise do substrato empregado no experimento para as concentrações disponíveis dos nutrientes.

\begin{tabular}{|c|c|c|c|c|c|c|c|}
\hline pH & $\mathbf{C E}$ & N-Nitrato & $\mathbf{P}$ & Cloreto & $\mathbf{S}$ & N-Amônio & $\mathbf{K}$ \\
\hline & $\mathrm{dS} / \mathrm{m}$ & \multicolumn{6}{|c|}{ 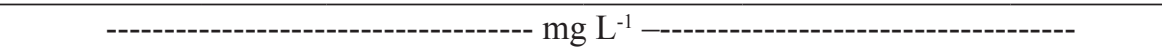 } \\
\hline 5,5 & 1,6 & 121,9 & 6,2 & 19,2 & 60,0 & 5,8 & 126,0 \\
\hline $\mathbf{N a}$ & Ca & Mg & B & $\mathrm{Cu}$ & Fe & Mn & $\mathbf{Z n}$ \\
\hline & -------- & ------ & --- & 1 '------- & - & --1-- & \\
\hline 8,7 & 149,5 & 61,1 & 0,1 & $<0,01$ & 0,02 & 0,1 & 0,02 \\
\hline
\end{tabular}

Método de extração: 1:1,5 (Holanda). Métodos de determinação: N-(amoniacal e nitrato): destilação; K, Ca, Mg, P ,S, Cu, Fe, Mn, $\mathrm{Zn}$ : ICP-OES.

Fonte: Instituto Agronômico de Campinas (IAC).

O delineamento experimental adotado foi em blocos casualizados, em esquema fatorial $4 \times 4$, sendo 4 doses de nitrogênio, 4 doses de potássio, com 3 repetições e 3 plantas por parcela, totalizando 144 mudas.

As doses de $\mathrm{N}$ e $\mathrm{K}$ empregadas foram baseadas na marcha de absorção de mudas de goiabeiras, determinadas em hidroponia por Franco et al. (2007), sendo: 0, 552 (dose padrão), 828 e 1.104 mg de $\mathrm{N} \mathrm{dm}^{-3}$ de substrato; e 0,726 (dose padrão), 1.089 e $1.452 \mathrm{mg}$ de $\mathrm{K} \mathrm{dm}^{-3}$ de substrato. Utilizouse, portanto, além das doses zero e padrão, uma vez e meia e duas vezes a dose padrão, devido ao valor encontrado em hidroponia ser considerado o mínimo necessário para o desenvolvimento das mudas até 120 dias. As fontes de adubos utilizados foram uréia e cloreto de potássio, sendo as aplicações realizadas de forma manual e superficialmente a cada 30 dias, em três parcelas (divididas em partes iguais por aplicação), sendo a primeira um mês após o transplantio para o viveiro.
Aos 120 dias, as mudas apresentavam altura próxima a $50 \mathrm{~cm}$, sendo neste momento avaliadas as seguintes características biométricas: altura, medida do colo da muda até a gema apical; diâmetro do caule, avaliado com paquímetro, a 8-10 centímetros do colo da muda, e número de folhas. Neste momento foi realizada, também, a leitura do índice SPAD (Soil Plant Analysis Development), com clorofilômetro (SPAD Minolta 502), no terceiro par de folhas, segundo recomendação de Natale et al. (1996), confirmado por Rozane et al. (2009) para mudas de goiabeira. No terceiro par de folhas (do ápice para a base do ramo) a leitura foi realizada na região medial do limbo foliar, em uma das folhas do par.

O material vegetal foi separado em caule, folhas e raízes, sendo colocado em estufa com circulação forçada de ar e temperatura entre $65-70{ }^{\circ} \mathrm{C}$, até massa constante. Determinou-se, assim, a massa de matéria seca de cada um dos órgãos das plantas e, com a soma destes, a massa de matéria seca total. 
De posse das características biométricas: altura (H), diâmetro (D), matéria seca da parte aérea (caule + folhas) (MSPA), raízes (MSR) e matéria seca total (MST), calculou-se o índice de qualidade de Dickson (IQD) para mudas, por meio da fórmula (DICKSON; LEAF; HOSNER, 1960):

\section{IQD $=$ MST $/((H / D)+(M S P A / M S R))$}

Realizou-se, também, a determinação dos teores de macronutrientes $(\mathrm{N}, \mathrm{P}, \mathrm{K}, \mathrm{Ca}, \mathrm{Mg}, \mathrm{S})$ e micronutrientes $(\mathrm{B}, \mathrm{Cu}, \mathrm{Fe}, \mathrm{Mn}, \mathrm{Zn})$ nas folhas, caule e raízes, segundo metodologia de Bataglia et al. (1983), bem como o acúmulo de nutrientes (correspondente ao produto entre teor e matéria seca) em cada um dos órgãos, obtendo-se o acúmulo total (planta).

Determinou-se, ainda, a partir da matéria seca e teores de $\mathrm{N}$ e K na planta, os índices: eficiência de absorção $=$ (conteúdo total do nutriente na planta)/(matéria seca de raízes), conforme Swiader, Chyan e Freiji (1994); eficiência de transporte = ((conteúdo do nutriente na parte aérea)/ (conteúdo total do nutriente na planta))x100, de acordo com Li, Mckeand e Allen (1991); eficiência de utilização $=(\text { matéria seca total produzida })^{2} /($ conteúdo total do nutriente na planta), segundo Siddiqi e Glass (1981).

Com base nos resultados obtidos, realizou-se a análise de variância para as diversas características estudadas e a análise de regressão para as doses de nitrogênio, potássio e interações, quando significativas pelo teste F, com auxílio do programa estatístico SISVAR (FERREIRA, 2008).

\section{Resultados e Discussão}

\section{Dados biométricos, indice SPAD e IQD}

As mudas de goiabeira responderam à adição de $\mathrm{N}$ em relação aos dados biométricos, índice SPAD e IQD, com exceção da massa seca das raízes, sendo o modelo quadrático o que melhor se ajustou aos atributos avaliados (Figuras 1, 2, 3 e Tabela 3). Almeida et al. (2006) e Mendonça et al. (2007) observaram efeitos significativos das doses de $\mathrm{N}$ sobre a altura, o número de folhas, a massa seca da parte aérea e das raízes de mudas de maracujazeiroamarelo. O mesmo foi relatado por Mendonça et al. (2006) para mudas de mamoeiro 'Formosa'.

Tabela 3. Efeito da adubação nitrogenada sobre o diâmetro do caule, número de folhas, massa seca de folhas e de caule e IQD, em mudas de goiabeira.

\begin{tabular}{lccc}
\hline \multicolumn{1}{c}{ Variável } & Doses de N & $\mathbf{R}^{2}$ & $\mathbf{F}$ \\
\hline Diâmetro do caule & $\mathrm{y}=-0,0000003 \mathrm{x}^{2}+0,0004 \mathrm{x}+0,2317$ & 0,98 & $19,69^{*}$ \\
Número de folhas & $\mathrm{y}=-0,00001 \mathrm{x}^{2}+0,0154 \mathrm{x}+10,3$ & 0,99 & $16,83^{* *}$ \\
Massa seca das folhas & $\mathrm{y}=-0,000006 \mathrm{x}^{2}+0,0097 \mathrm{x}+3,6422$ & 0,98 & $17,24^{* *}$ \\
Massa seca do caule & $\mathrm{y}=0,000004 \mathrm{x}^{2}+0,0057 \mathrm{x}+0,8728$ & 0,99 & $19,97^{* *}$ \\
IQD & $\mathrm{y}=-0,00000005 \mathrm{x}^{2}+0,00008 \mathrm{x}+0,06$ & 0,99 & $4,44^{*}$ \\
\hline
\end{tabular}

Fonte: Elaboração dos autores.

As doses de $\mathrm{K}$ e a interação $\mathrm{N}$ x $\mathrm{K}$, não apresentaram diferença significativa sobre os atributos estudados. Ferreira et al. (2008) também não obtiveram efeitos significativos da aplicação de $\mathrm{K}$ sobre a altura, a massa seca da parte aérea e das raízes de mudas de tamarindeiro. Uma possível explicação para o efeito não significativo é de que a reserva de $\mathrm{K}$ encontrada nos ramos que se utilizam para a propagação vegetativa das mudas de goiabeira, ou que o teor de K presente no substrato, tenham sido suficientes para o desenvolvimento inicial das mudas, haja vista que nenhum sintoma visual de carência de potássio foi observado durante a condução do experimento.

Na Figura 1 verifica-se que a maior altura está associada à dose de $762 \mathrm{mg} \mathrm{de} \mathrm{N} \mathrm{dm}^{-3}$, alcançando 
$57,1 \mathrm{~cm}$, proporcionando ganho de $29 \mathrm{~cm}$ em altura, quando comparada à testemunha (Tabela 4). Essa dose é $210 \mathrm{mg}$ de $\mathrm{N} \mathrm{dm}^{-3}$ mais elevada que a obtida por Franco et al. (2007) em cultivo hidropônico de goiabeiras. A utilização da altura das plantas para estimar a qualidade das mudas pode ser empregada, além de sua medição ser fácil, não é um método destrutivo (GOMES et al., 2002) e estar ao alcance de todos os produtores.

Tabela 4. Doses de nitrogênio para a obtenção da produção máxima da variável analisada e porcentagem de ganho da diferença entre o ponto de máxima e a testemunha.

\begin{tabular}{lccc}
\hline \multicolumn{1}{c}{ Variável } & $\begin{array}{c}\text { Ponto de } \\
\text { máxima }\end{array}$ & $\begin{array}{c}\text { Dose de N para ponto de } \\
\text { máxima }\end{array}$ & Ganhos em relação à testemunha \\
\hline & & $--\mathrm{mg} \mathrm{de} \mathrm{N} \mathrm{dm}^{-3}--$ & $-----\%----$ \\
Altura $(\mathbf{c m})$ & 57,10 & 762 & 103 \\
Diâmetro $(\mathbf{m m})$ & 0,62 & 667 & 60 \\
Número de folhas & 16,20 & 770 & 57 \\
Índice SPAD & 44,37 & 793 & 23 \\
Matéria seca de folhas $(\mathbf{g})$ & 7,56 & 808 & 107 \\
Matéria seca de caule $(\mathrm{g})$ & 2,90 & 713 & 232 \\
Matéria seca total $(\mathbf{g})$ & 15,40 & 865 & 94 \\
IQD & 0,099 & 800 & 47 \\
\hline
\end{tabular}

Fonte: Elaboração dos autores.

Figura 1. Efeito de doses de nitrogênio $(\mathrm{N})$ sobre a altura de mudas de goiabeira.

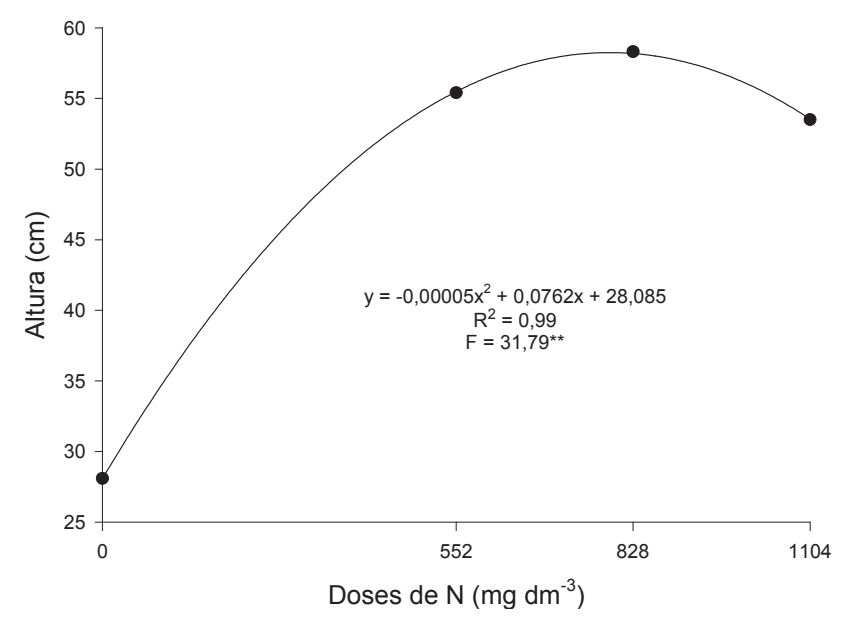

Fonte: Elaboração dos autores.

O valor máximo do índice SPAD $(44,37)$ foi obtido com a dose de $793 \mathrm{mg}$ de $\mathrm{N} \mathrm{dm}^{-3}$ (Figura 2 e Tabela 4). Em trabalho que avaliou doses de NPK em mudas de limoeiro-cravo, Prado e Vale (2008) concluíram que houve correlação positiva entre a leitura SPAD e o teor de N nas folhas e, também, com a produção de matéria seca, indicando que a medida indireta da clorofila foi adequada para a avaliação do estado nutricional de nitrogênio. Rozane et al. (2009) também constataram que o índice SPAD é uma ferramenta eficiente para o diagnóstico nutricional de $\mathrm{N}$ em mudas de goiabeira. 
Figura 2. Efeito de doses de nitrogênio (N) sobre o índice SPAD em mudas de goiabeira.

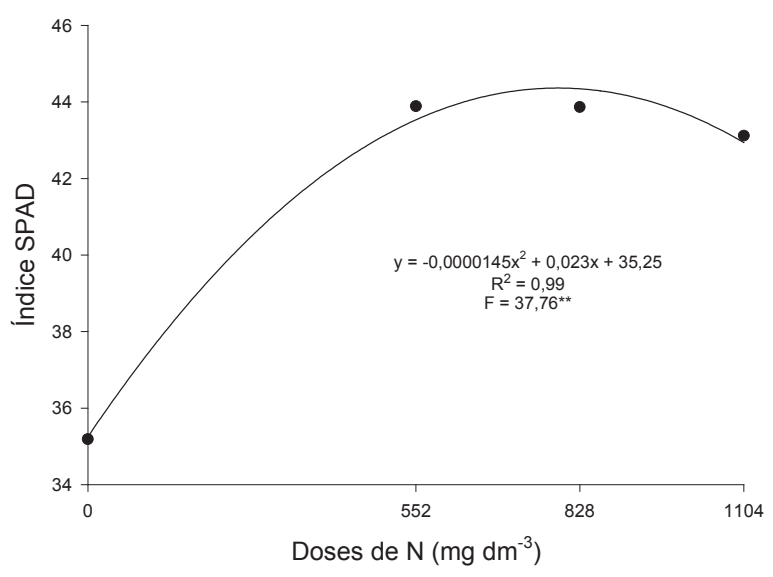

Fonte: Elaboração dos autores.

Para a massa da matéria seca total, a dose de $865 \mathrm{mg}$ de $\mathrm{N} \mathrm{dm}^{-3}$ proporcionou valor máximo, correspondendo a 15,4 g (Figura 3), que promoveu ganho de $94 \%$ em relação à testemunha (Tabela
4). Algumas pesquisas com mudas utilizaram a massa de matéria seca total para demonstrar o desenvolvimento adequado das plantas (SOUZA et al., 2007, MENDONÇA et al., 2009), apesar do produtor de mudas preferir a altura.

Figura 3. Efeito de doses de nitrogênio $(\mathrm{N})$ sobre a massa de matéria seca total de mudas de goiabeira.



Fonte: Elaboração dos autores.

A dose que promoveu o máximo índice de qualidade de Dickson (IQD) foi de $800 \mathrm{mg} \mathrm{dm}^{-3}$ de N, estando associada ao IQD de 0,099 (Tabela 4). Quanto maior o IQD, melhor será a qualidade da muda produzida (GOMES, 2001). Este índice é tradicionalmente utilizado na produção de mudas de espécies florestais, mas as mesmas características que compõe o IQD são importantes para a produção de mudas frutíferas.

De maneira geral, as variáveis biométricas, leitura SPAD, massas de matéria seca e mesmo o IQD sofreram efeito depressivo a partir de 
determinada dose de nitrogênio aplicada. Uma possível explicação pode ser a acidificação do meio, haja vista que o adubo utilizado foi a uréia $\left[\mathrm{CO}\left(\mathrm{NH}_{2}\right)_{2}\right]$, cujo desdobramento pela urease libera $\mathrm{H}^{+}$(MALAVOLTA, 2006). Os resultados apresentados corroboram com aqueles de Decarlos Neto et al. (2002), que verificaram queda das variáveis biométricas e da massa de matéria seca em mudas de citrus, em função do incremento das doses de N.

Uma informação importante obtida no presente estudo é que a dose indicada por Franco et al. (2007) (552 $\mathrm{mg}$ de $\mathrm{N} \mathrm{dm}^{-3}$ ) está aquém das doses que permitiram maximizar os valores das variáveis analisadas. Entretanto, aqueles autores trabalharam com mudas de goiabeira em condições de hidroponia.

\section{Acúmulo de nutrientes}

Não houve diferença significativa da interação das doses ( $\mathrm{N}$ x K) em relação aos acúmulos de nutrientes (Tabela 5). Para as doses de $\mathrm{N}$ houve efeito significativo, a $1 \%$ de probabilidade, nos acúmulos de N, P, K, Ca, B, Mn e Zn e, de 5\%, em relação ao $\mathrm{S}$ (Tabela 5). Para as doses de $\mathrm{K}$ houve efeito significativo em relação aos acúmulos de K, $\mathrm{Cu}$ e $\mathrm{Zn}$ (Tabela 5).

Tabela 5. Efeito da adubação nitrogenada e potássica no acúmulo total dos nutrientes em mudas de goiabeira.

\begin{tabular}{|c|c|c|c|}
\hline Nutriente & Doses de N & $\mathbf{R}^{2}$ & $\mathbf{F}$ \\
\hline $\mathrm{N}$ & $y=-0,00002 x 2+0,3294 x+99,155$ & 0,98 & $21,38^{* *}$ \\
\hline K & $y=-0,00015 x 2+0,2662 x+138,43$ & 0,95 & $8,10 * *$ \\
\hline $\mathrm{P}$ & $y=-0,00002 x^{2}+0,0302 x+16,682$ & 0,97 & $9,26 * *$ \\
\hline $\mathrm{Ca}$ & $y=-0,00008 x^{2}+0,1222 x+67,251$ & 0,99 & $13,27 * *$ \\
\hline S & $y=0,0044 x+15,031$ & 0,96 & $8,03 * *$ \\
\hline B & $y=-0,0004 x^{2}+0,6991 x+423,26$ & 0,99 & $8,18 * *$ \\
\hline Mn & $y=-0,0006 x^{2}+2,0325 x+891,97$ & 0,99 & $6,42 *$ \\
\hline $\mathrm{Zn}$ & $y=-0,0004 x^{2}+0,6076 x+317,43$ & 0,94 & $13,33^{* *}$ \\
\hline Nutriente & Doses de K & $\mathbf{R}^{2}$ & $\mathbf{F}$ \\
\hline $\mathrm{K}$ & $y=0,1149 x+127,76$ & 0,92 & $33,39 * *$ \\
\hline $\mathrm{Cu}$ & $y=0,0277 x+35,496$ & 0,83 & $18,44^{* *}$ \\
\hline $\mathrm{Zn}$ & $y=0,1422 x+350,81$ & 0,77 & $18,73 * *$ \\
\hline
\end{tabular}

$* *$ e $*$ significativo a $1 \%$ e $5 \%$ de probabilidade, respectivamente, pelo teste $\mathrm{F}$.

Fonte: Elaboração dos autores.

Quanto ao acúmulo de $\mathrm{N}$ e $\mathrm{K}$, em resposta à adubação nitrogenada, o modelo quadrático foi o que melhor se ajustou aos dados (Tabela 5). A dose que proporcionou maior acúmulo de $\mathrm{N}(357 \mathrm{mg})$ foi de $824 \mathrm{mg}$ de $\mathrm{N} \mathrm{dm}^{-3}$, enquanto para o acúmulo de $\mathrm{K}$, a melhor dose foi $888 \mathrm{mg} \mathrm{de} \mathrm{N} \mathrm{dm}^{-3}$, obtendo-se $257 \mathrm{mg}$ de K por planta.

Houve uma reposta linear crescente do acúmulo de K, em função da aplicação de potássio. Verificase que o modelo que melhor se ajustou aos acúmulos de P, K, Ca, B, Mn e Zn foi o quadrático e, para o nutriente $\mathrm{S}$, o linear, em função da adubação nitrogenada. Para o acúmulo de $\mathrm{Cu}$ e $\mathrm{Zn}$ o melhor modelo foi o linear em função da adubação potássica (Tabela 5).

Franco et al. (2007) verificaram para mudas de goiabeira da cv. Paluma o acúmulo total de 726; 552; 293; 73; 64 e 39 mg por planta, para K, N, Ca, $\mathrm{S}, \mathrm{P}$ e $\mathrm{Mg}$, respectivamente. Para micronutrientes, os mesmos autores verificaram o acúmulo total de: 
$632 ; 134 ; 8.103 ; 3052$ e $760 \mu \mathrm{g}$ por planta para $\mathrm{B}$, $\mathrm{Cu}, \mathrm{Fe}, \mathrm{Mn}$ e $\mathrm{Zn}$.

Em estudo avaliando as eficiências de absorção de nutrientes em mudas de goiabeira Paluma, Prado e Franco (2007) constataram que as maiores taxas de acumulação organogênica do $\mathrm{N}$ e do K estiveram nos seguintes intervalos em ordem decrescente: 75-90, 30-45 e 45-60 dias de cultivo das mudas, as quais se aproximam dos intervalos usados para adubação parcelada de NK no presente estudo (30, 60 e 90 dias de cultivo, após o transplante para o telado).
Apesar de não ter sido encontrado resultado significativo para as variáveis biométricas e, mesmo de matéria seca em função das doses de potássio empregadas, quando se avalia o acúmulo de $\mathrm{K}$ na planta verifica-se grande absorção do nutriente, caracterizando, assim, consumo de luxo pela muda.

\section{Eficiência de absorção, utilização e transporte}

$\mathrm{Na}$ Tabela 6, observa-se comportamento quadrático para eficiência de absorção de $\mathrm{N}$ em função das doses de $\mathrm{K}$ empregadas, exceto para a dose de $1.089 \mathrm{mg} \mathrm{dm}^{-3}$, a qual foi linear crescente, com o incremento da fertilização nitrogenada.

Tabela 6. Efeito da adubação nitrogenada e potássica nas eficiências de absorção, transporte e utilização de nitrogênio e potássio em mudas de goiabeira.

\begin{tabular}{|c|c|c|c|}
\hline Doses de K & Doses de N & $\mathbf{R}^{2}$ & $\mathbf{F}$ \\
\hline \multicolumn{4}{|c|}{ Eficiência de absorção de $\mathbf{N}$} \\
\hline $0 \mathrm{mg} \mathrm{dm}^{-3}$ & $\mathbf{y}=-0,00007 x^{2}+0,1026 x+23,981$ & 0,98 & $29,40 * *$ \\
\hline $726 \mathrm{mg} \mathrm{dm}^{-3}$ & $y=-0,00001 x^{2}+0,0536 x+21,853$ & 0,93 & $6,43 * *$ \\
\hline $1089 \mathrm{mg} \mathrm{dm}^{-3}$ & $y=0,0267 x+35,558$ & 0,82 & $23,79 * *$ \\
\hline $1452 \mathrm{mg} \mathrm{dm}^{-3}$ & $\mathbf{y}=-0,00004 \times 2+0,0544 x+36,479$ & 0,71 & $10,78 * *$ \\
\hline \multicolumn{4}{|c|}{ Eficiência de absorção de $K$} \\
\hline $726 \mathrm{mg} \mathrm{dm}^{-3}$ & $y=-0,00004 x^{2}+0,0749+30,404$ & 0,87 & $7,56^{* *}$ \\
\hline $1089 \mathrm{mg} \mathrm{dm}^{-3}$ & $y=0,0195 x+54,302$ & 0,37 & $5,51 *$ \\
\hline $1452 \mathrm{mg} \mathrm{dm}^{-3}$ & $y=-0,00005 x^{2}+0,0656 x+49,245$ & 0,64 & $7,93 * *$ \\
\hline \multicolumn{4}{|c|}{ Eficiência de transporte de $\mathrm{N}$} \\
\hline $0 \mathrm{mg} \mathrm{dm}^{-3}$ & $\mathbf{y}=-0,00003 x^{2}+0,0392 x+71,612$ & 0,99 & $19,65^{* *}$ \\
\hline $726 \mathrm{mg} \mathrm{dm}^{-3}$ & $y=-0,00002 x^{2}+0,0276 x+71,054$ & 0,99 & $8,54 * *$ \\
\hline $1452 \mathrm{mg} \mathrm{dm}^{-3}$ & $\mathbf{y}=-0,00002 x^{2}+0,0216 x+79,115$ & 0,81 & $8,44 * *$ \\
\hline \multicolumn{4}{|c|}{ Eficiência de transporte de $K$} \\
\hline $0 \mathrm{mg} \mathrm{dm}^{-3}$ & $\mathbf{y}=-0,00002 x^{2}+0,0291 x+76,764$ & 0,97 & $7,81 * *$ \\
\hline $726 \mathrm{mg} \mathrm{dm}^{-3}$ & $y=0,016 x+70,286$ & 0,88 & $28,72 * *$ \\
\hline \multicolumn{4}{|c|}{ Eficiência de utilização de $K$} \\
\hline $0 \mathrm{mg} \mathrm{dm}^{-3}$ & $\mathbf{y}=-0,000004 x^{2}+0,0051 x+0,4693$ & 0,94 & $6,31 *$ \\
\hline
\end{tabular}

Fonte: Elaboração dos autores.

Houve, também, significância para a eficiência de absorção de K em função da aplicação de N, com exceção da dose $0 \mathrm{mg} \mathrm{dm}^{-3}$ de $\mathrm{K}$ (Tabela 6). Observa-se comportamento quadrático para as doses 726 e $1.452 \mathrm{mg} \mathrm{dm}^{-3}$ de $\mathrm{K}$ e linear crescente para a dose $1.089 \mathrm{mg} \mathrm{dm}^{-3}$ de K(Tabela 6).
Franco et al. (2007) constataram que os nutrientes mais absorvidos por mudas de goiabeiras são o nitrogênio e o potássio. Rozane et al. (2007), em trabalho avaliando a eficiência de absorção de nutrientes em mudas de caramboleira, constataram que houve diferenças nas soluções nutritivas para a eficiência de absorção de potássio; embora, os 
autores tenham trabalhado em cultivo hidropônico, as soluções apresentam concentrações diferentes de elementos.

Franco e Prado (2006), em estudo com soluções nutritivas, também observaram diferenças na eficiência de absorção de $\mathrm{N}$ em mudas de goiabeira, sendo que a maior eficiência esteve associada à solução nutritiva com menor concentração do nutriente.

As maiores eficiências de absorção de nitrogênio e potássio estiveram associadas à interação das seguintes doses: $1.104 \mathrm{mg}$ de $\mathrm{N} \mathrm{dm}^{-3}$ e $1.089 \mathrm{mg}$ de $\mathrm{K} \mathrm{dm}^{-3}$ (Tabela 6).

Na Tabela 6 nota-se que a eficiência de transporte de $\mathrm{N}$ seguiu o comportamento quadrático para as doses 0,726 e $1.452 \mathrm{mg}$ de $\mathrm{K} \mathrm{dm}^{-3}$ em função das doses de N.

O modelo que melhor se ajustou à eficiência de transporte de $\mathrm{K}$ foi o quadrático para a dose $0 \mathrm{e}$ linear para a dose $726 \mathrm{mg}$ de $\mathrm{K} \mathrm{dm}^{-3}$, em relação à adubação nitrogenada; no entanto, para as demais doses de potássio estudadas não houve resposta significativa (Tabela 6).

Considerando-se a eficiência de transporte, como sendo a capacidade da planta de transportar os nutrientes das raízes para a parte aérea, verificase para o nitrogênio e o potássio que todas as curvas de resposta foram quadráticas, ou seja, há uma dose ótima, dependendo das quantidades do nutriente transportadas para parte aérea. Uma possível explicação seria a interação de nutrientes, visto que ambos os elementos são móveis no xilema.

A interação de doses que proporcionou a maior eficiência de transporte para nitrogênio foi $540 \mathrm{mg}$ $\mathrm{dm}^{-3}$ de $\mathrm{N}$ com $1.452 \mathrm{mg} \mathrm{dm}{ }^{-3}$ de $\mathrm{K}$, com 84,9\%; já para eficiência de transporte de potássio, a utilização de $726 \mathrm{mg} \mathrm{dm}^{-3}$ de $\mathrm{K}$, com o incremento da adubação nitrogenada.

Rozane et al. (2007), em estudo hidropônico com mudas de caramboleira, verificaram que para eficiência de transporte de nitrogênio houve diferenças entre soluções nutritivas, as quais variam em função da concentração do elemento.

Observa-se na Tabela 6 resultado significativo entre interação $\mathrm{N}$ x K e a eficiência de utilização de $\mathrm{K}$ apenas para a dose de $0 \mathrm{mg}$ de $\mathrm{K} \mathrm{dm}^{-3}$, cujo melhor modelo de resposta foi o quadrático em função das doses de N. A dose que promoveu maior eficiência de utilização de potássio foi de $637 \mathrm{mg} \mathrm{dm}^{-3} \mathrm{de} \mathrm{N}$.

Em estudo da eficiência de absorção de nutrientes em mudas de goiabeiras cultivadas em diferentes soluções nutritivas, Franco e Prado (2006) constataram que houve diferenças entre as eficiências de utilização de $\mathrm{N}$ nas soluções empregadas. Já Rozane et al. (2007), em estudo semelhante, porém com mudas de caramboleira, não verificaram diferenças na eficiência de utilização de nitrogênio pelas mudas. Os autores indicaram que as mudas foram conduzidas em ambiente adequado, sem estresse e/ou falta de nutrientes.

Ronchi et al. (2001), estudando doses de nitrogênio em solução nutritiva e em solo para tomateiro, constataram que não houve diferenças na eficiência de utilização de $\mathrm{N}$, nas doses empregadas, porém, apenas entre sistemas de condução (hidroponia e solo), sendo que em cultivo com solução nutritiva a maior eficiência foi devido a maior disponibilidade de água e de outros nutrientes.

A aplicação de $800 \mathrm{mg} \mathrm{dm}^{-3}$ de $\mathrm{N}$ e de $1.452 \mathrm{mg}$ $\mathrm{dm}^{-3}$ de K promoveram bons resultados na produção de mudas de goiabeira.

\section{Conclusões}

Houve efeito significativo das doses de nitrogênio aplicadas sobre as mudas de goiabeira nas variáveis: altura, diâmetro do caule, número de folhas, índice SPAD, massa seca de folhas, caule, total, IQD, acúmulo de N.

A adubação com potássio não promoveu diferenças significativas nos parâmetros biométricos, índice SPAD e IQD, porém, houve 
efeito significativo quanto ao acúmulo de $\mathrm{K}$, bem como nas eficiências de absorção e utilização.

\section{Agradecimentos}

À FAPESP pela bolsa de IC ao primeiro autor (Processo n²009/11524-5) e a FUNDUNESP pelo auxílio à pesquisa (Processo $n^{\circ} 00031 / 10$-DFP).

Aos irmãos José Mauro da Silva e João Mateus da Silva pela oportunidade de realização do experimento no viveiro de mudas do Sítio São João - Taquaritinga-SP.

\section{Referências}

ALMEIDA, E. V.; NATALE, W.; PRADO, R. M.; BARBOSA, J. C. Adubação nitrogenada e potássica no desenvolvimento de mudas de maracujazeiro. Ciência Rural, Santa Maria, v. 36, n. 4, p. 1138-1142, 2006.

BATAGLIA, O. C.; FURLANI, A. M. C.; TEIXEIRA, J. P. F.; FURLANI, P. R.; GALLO, J. R. Métodos de análise química de plantas. Campinas: Instituto Agronômico, 1983. 48 p. (Boletim técnico, 78).

BOAVENTURA, P. R. R.; QUAGGIO, J. A.; ABREU, M. F.; BATAGLIA, O. C. Balanço de nutrientes na produção de mudas cítricas cultivadas em substrato. Revista Brasileira de Fruticultura, Jaboticabal, v. 26, n. 2, p. 300-305, 2004.

CORREAA, M. C. M.; PRADO, R. M.; NATALE, W.; PEREIRA, L.; BARBOSA, J. C. Respostas de mudas de goiabeira a doses e modos de aplicação de fertilizante fosfatado. Revista Brasileira de Fruticultura, Jaboticabal, v. 25 , n. 1, p. 164-169, 2003.

DECARLOS NETO, A.; SIQUEIRA, D. L.; PEREIRA, P. R. G.; ALVAREZ, V. V. H. Crescimento de portaenxertos de citros em tubetes influenciados por doses de N. Revista Brasileira de Fruticultura, Jaboticabal, v. 24, n. 1, p. 199-203, 2002.

DICKSON, A.; LEAF, A. L.; HOSNER, J. F. Quality appraisal of white spruce and white pine seedling stock in nurseries. The Forest Chronicle, Ottawa, v. 36, n. 1, p. 10-13, 1960 .

FERREIRA, D. F. Sisvar: um programa para análises e ensino estatístico. Revista Científica Symposium, Lavras, v. 6, n. 2, p. 36-41, 2008.
FERREIRA, E. A.; MENDONÇA, V.; SOUZA, H. A.; RAMOS, J. D. Adubação fosfatada e potássica na formação de mudas de tamarindeiro. Revista Scientia Agraria, Curitiba, v. 9, n. 4, p. 475-480, 2008.

FRANCO, C. F.; PRADO, R. M. Uso de soluções nutritivas no desenvolvimento e no estado nutricional de mudas de goiabeira: macronutrientes. Acta Scientiarum Agronomy, Maringá, v. 28, n. 2, p. 199-205, 2006.

FRANCO, F. C.; PRADO, R. M.; BRACHIROLLI, L. F.; ROZANE, D. E. Curva de crescimento e marcha de absorção de macronutrientes em mudas de goiabeira. Revista Brasileira de Ciência do Solo, Viçosa, v. 31, n. 6, p. 1429-1437, 2007.

GOMES, J. M. Parâmetros morfológicos na avaliação da qualidade de mudas de Eucalyptus grandis, produzidas em diferentes tamanhos de tubete e de dosagens de $N-P-K$. 2001. Tese (Doutorado em Ciências Florestais) Universidade Federal de Viçosa, Viçosa.

GOMES, J. M.; COUTO, L.; LEITE, H. G.; XAVIER, A.; GARCIA, S. L. R. Parâmetros morfológicos na avaliação da qualidade das mudas de Eucalyptus grandis. Revista Árvore, Viçosa, v. 26, n. 6, p. 655-664, 2002.

LI, B.; MCKEAND, S. E.; ALLEN, H. L. Genetic variation in nitrogen use efficiency of loblolly pine seedlings. Forest Science, Madison, v. 37, n. 2, p. 613626, 1991.

MALAVOLTA, E. Manual de nutrição mineral de plantas. São Paulo: Agronômica Ceres, 2006. 638 p.

MENDONÇA, V.; FERREIRA, E. A.; PAULA, Y. C. M.; BATISTA, T. M. V; RAMOS, J. D. Crescimento de mudas de maracujazeiro-amarelo influenciado por doses de nitrogênio e de superfosfato simples. Revista Caatinga, Mossoró, v. 20, n. 4, p. 137-143, 2007.

MENDONÇA, V.; PEDROSA, C.; FELDBERG, N. P.; ABREU, N. A. A.; BRITO, A. P. F.; RAMOS, J. D. Doses de nitrogênio e superfosfato simples no crescimento de mudas de mamoeiro Formosa. Ciência e Agrotecnologia, Lavras, v. 30, n. 6, p. 1065-1070, 2006.

MENDONÇA, V.; RAMOS, J. D.; ABREU, N. A. A.; TEIXEIRA, G. A.; SOUZA, H. A.; GURGEL, R. L. S.; ORBES, M. Y. Adubação nitrogenada em cobertura na formação e substratos na formação de mudas de mamoeiro 'Formosa'. Ciência e Agrotecnologia, Lavras, v. 33, n. 3, p. 668-675, 2009.

NATALE, W.; COUTINHO, E. L. M.; BOARETTO, A. E.; PEREIRA, F. M. Goiabeira: calagem e adubação. Jaboticabal: FUNEP, 1996. 22 p. 
PRADO, R. M.; FRANCO, C. F. Eficiência de absorção de nutrientes em mudas de goiabeira Paluma e Século XXI, cultivadas em solução nutritiva. Revista Brasileira de Ciências Agrárias, Recife, v. 2, n. 4, p. 275-280, 2007.

PRADO, R. M.; VALE, D. W. Nitrogênio, fósforo e potássio na leitura SPAD em porta-enxerto de limoeiro cravo. Pesquisa Agropecuária Tropical, Goiânia, v. 38, n. 4, p. 272-232, 2008.

RONCHI, C. P.; FONTES, P. C. R.; PEREIRA, P. R. G.; NUNES, J. C. S.; MARTINEZ, H. E. P. Índices de nitrogênio e de crescimento do tomateiro em solo e solução nutritiva. Revista Ceres, Viçosa, v. 48, n. 278, p. 469-484, 2001.

ROZANE, D. E.; PRADO, R. M.; FRANCO, C. F.; NATALE, W. Eficiência de absorção, transporte e utilização de macronutrientes por porta-enxertos de caramboleira, cultivados em soluções nutritivas. Ciência e Agrotecnologia, Lavras, v. 31, n. 4, p. 1020-1026, 2007.
ROZANE, D. E.; SOUZA, H. A.; PRADO, R. M.; NATALE, W.; FRANCO, C. F.; LEAL, R. M. Influência do cultivar, tipo de folha e do tempo de cultivo na medida indireta de clorofila (SPAD) em mudas de goiabeira. Ciência e Agrotecnologia, Lavras, v. 33, n. 6, p. 15381543, 2009.

SIDDIQI, M.Y.; GLASS, A. D. M. Utilization index: a modified approach to the estimation and comparison of nutrient efficiency in plants. Journal of Plant Nutrition, v. 4, n. 3, p. 289-302, 1981.

SOUZA, H. A.; MENDONÇA, V.; ABREU, N. A. A.; TEIXEIRA, G. A.; GURGEL, R. L. S.; RAMOS, J. D. Adubação nitrogenada e substratos na produção de mudas de maracujazeiro doce. Ciência e Agrotecnologia, Lavras, v. 31, n. 3, p. 599-604, 2007.

SWIADER, J. M.; CHYAN, Y.; FREIJI, F. G. Genotypic differences in nitrate uptake and utilization efficiency in pumpkin hybrids. Journal of Plant Nutrition, Monticello, v. 17, n. 10, p. 1687-1699, 1994. 
